\title{
Attenuated transforming growth factor beta signaling promotes metastasis in a model of HER2 mammary carcinogenesis
}

Sergey V Novitskiy ${ }^{1 \dagger}$, Elizabeth Forrester ${ }^{1 \dagger}$, Michael W Pickup ${ }^{1}$, Agnieszka E Gorska', Anna Chytil ${ }^{1}$, Mary Aakre ${ }^{1}$, Dina Polosukhina 2 , Philip Owens', Dilyara R Yusupova ${ }^{3}$, Zhiguo Zhao ${ }^{4}$, Fei Ye ${ }^{4}$, Yu Shyr ${ }^{4}$ and Harold L Moses ${ }^{1,5^{*}}$

\begin{abstract}
Introduction: Transforming growth factor beta (TGF $\beta$ ) plays a major role in the regulation of tumor initiation, progression, and metastasis. It is depended on the type II TGF $\beta$ receptor (TRRII) for signaling. Previously, we have shown that deletion of T $\beta R I I$ in mammary epithelial of MMTV-PyMT mice results in shortened tumor latency and increased lung metastases. However, active TGF $\beta$ signaling increased the number of circulating tumor cells and metastases in MMTV-Neu mice. In the current study, we describe a newly discovered connection between attenuated TGF $\beta$ signaling and human epidermal growth factor receptor 2 (HER2) signaling in mammary tumor progression.
\end{abstract}

Methods: All studies were performed on MMTV-Neu mice with and without dominant-negative TßRII (DNIIR) in mammary epithelium. Mammary tumors were analyzed by flow cytometry, immunohistochemistry, and immunofluorescence staining. The levels of secreted proteins were measured by enzyme-linked immunosorbent assay. Whole-lung mount staining was used to quantitate lung metastasis. The Cancer Genome Atlas (TCGA) datasets were used to determine the relevance of our findings to human breast cancer.

Results: Attenuated TGF $\beta$ signaling led to a delay tumor onset, but increased the number of metastases in MMTVNeu/DNIIR mice. The DNIIR tumors were characterized by increased vasculogenesis, vessel leakage, and increased expression of vascular endothelial growth factor (VEGF). During DNIIR tumor progression, both the levels of CXCL1/5 and the number of CD11b+Gr1+ cells and T cells decreased. Analysis of TCGA datasets demonstrated a significant negative correlation between TGFBR2 and VEGF genes expression. Higher VEGFA expression correlated with shorter distant metastasis-free survival only in HER2+ patients with no differences in HER2-, estrogen receptor + /- or progesterone receptor +/- breast cancer patients.

Conclusion: Our studies provide insights into a novel mechanism by which epithelial TGF $\beta$ signaling modulates the tumor microenvironment, and by which it is involved in lung metastasis in HER2+ breast cancer patients. The effects of pharmacological targeting of the TGF $\beta$ pathway in vivo during tumor progression remain controversial. The targeting of TGF $\beta$ signaling should be a viable option, but because VEGF has a protumorigenic effect on HER2+ tumors, the targeting of this protein could be considered when it is associated with attenuated TGF $\beta$ signaling.

\footnotetext{
*Correspondence: hal.moses@vanderbilt.edu

${ }^{\dagger}$ Equal contributors

${ }^{1}$ Cancer Biology Department, Vanderbilt-Ingram Cancer Center, Nashville, TN, USA

${ }^{5}$ Vanderbilt University, 2220 Pierce Ave, PRB 612, Nashville, TN 37232, USA

Full list of author information is available at the end of the article
}

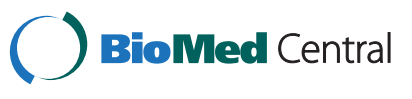

(c) 2014 Novitskiy et al.; licensee BioMed Central Ltd. This is an Open Access article distributed under the terms of the Creative Commons Attribution License (http://creativecommons.org/licenses/by/4.0), which permits unrestricted use, distribution, and reproduction in any medium, provided the original work is properly credited. The Creative Commons Public Domain Dedication waiver (http://creativecommons.org/publicdomain/zero/1.0/) applies to the data made available in this article, unless otherwise stated. 


\section{Introduction}

Transforming growth factor-beta (TGF $\beta$ ) is a homodimeric polypeptide, which includes three isoforms: TGF $\beta 1$, TGF $\beta 2$ and TGF $\beta 3$. Secreted TGF $\beta$ binds to TGF $\beta$ receptor II (T $\beta$ RII) and forms a heterodimeric complex with TGF $\beta$ receptor I (T $\beta R I)$. The activated T $\beta R I$ phosphorylates intracellular Smad2 and Smad3 (canonical TGF $\beta$ pathway). Simultaneously, phosphorylation of T $\beta$ RII activates PI3K, MAP3k1, PP2A, RHOA and others (non-canonical pathway) [1]. TGF $\beta$ plays a major role in the regulation of tumor initiation, progression, and metastasis, which requires T $\beta R I I$ for signaling [1].

It has been published that decreased expression or loss of TßRII correlates with an increased risk of developing invasive breast cancer [2]. Contrary to this fact, in mouse models of cancer, the inhibition of TGF $\beta$ signaling with the expression of dominant-negative TRRII (DNRII) or deletion of T $\beta$ RII increases cellular proliferation without initiating tumor development $[3,4]$. Therefore, the assumption is that attenuated TGF $\beta$ signaling alone is insufficient for transformation. In our previous research article it was indicated that deletion of T $\beta R I I$ in mammary epithelial of mouse mammary tumor virus (MMTV)-polyoma middle $\mathrm{T}$ antigen (PyMT) mice results in shortened tumor latency and a five-fold increase in lung metastases compared to MMTV-PyMT tumors with intact TGF $\beta$ signaling $[5,6]$. The mechanisms behind this phenotypic difference are correlated with the increased expression of CXCL1, CXCL5 and CCL20 $[7,8]$. Abrogated TGF $\beta$ signaling in carcinoma cells can indirectly promote progression of MMTV-PyMT tumor and metastasis by polarization $\mathrm{T}$ cells to Th17 cells via accumulation of $\mathrm{CD} 1 \mathrm{~b}^{+} \mathrm{Gr} 1^{+}$cells [9]. Additionally, epithelial TGF $\beta$ signaling regulates fibroblast recruitment and activation. Our recent article confirmed the fact that fibroblast-stimulated carcinoma cells utilize TGF $\beta$ signaling to drive single-cell migration, but migrate collectively in the absence of TGF $\beta$ signaling, which promotes mammary tumor invasion [10].

Mammary tumorigenesis has been examined through the use of numerous transgenic mouse models with wide utilization of the MMTV promoter/enhancer to drive expression in mammary epithelium. Overexpression of ErbB2 (Neu, human epidermal growth factor 2 (HER2)) or a constitutively active version of this receptor in the mammary epithelium leads to the development of metastatic mammary tumors [11-13]. Concurrently, overactivation of the ErbB2 pathway correlates with poor clinical prognosis in breast cancer patients [14]. Using Neu-induced mammary tumor models with increased activity of TGF $\beta$ signaling (MMTV/ALK5 and MMTV/TGF $\beta 1$ ), it was possible to induce that active TGF $\beta$ signaling accelerates metastasis and the number of circulating tumor cells [15-17]. The loss-of-function experiments through the expression of soluble betaglycan or a DNIIR has been reported to suppress metastasis in Neu-induced mammary tumors $[16,18]$.

Based on these data we decided to examine the connection between TGF $\beta$ and Neu signaling in mammary tumor progression using MMTV-Neu and MMTV-Neu activated induced tumorigenesis [13]. The transgenic strains in conjunction with mice expressing DNIIR were used in the mammary epithelium to investigate the effect of attenuated TGF $\beta$ signaling on tumorigenesis and metastasis. We found that attenuation of TGF $\beta$ signaling with DNIIR prolonged tumor latency and dramatically enhanced pulmonary metastasis. The mechanism was different from that reported for the MMTV-PyMT model with conditional deletion of T $\beta R I I$. Increased chemokine secretion through the knockout of carcinoma cells with resultant influx of

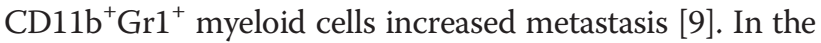
MMTV-Neu model with DNIIR, there was no difference in chemokine secretion increase by the carcinoma cells and no increase in immature myeloid cell infiltration. Instead, there was reported increased secretion of vascular endothelial growth factor (VEGF), diminished pericyte coverage of vessels, and increased vessel leakiness and vasculogenesis. These symptoms likely act as the mechanism for the increased number of metastases. Lastly, analysis of human breast cancer transcriptome databases demonstrated a significant correlation between decreased TGFBR2 and increased VEGFA gene expression similar to what was observed in the mouse models. Higher VEGFA gene expression was correlated with poor survival only in HER2positive (HER2+) patients.

\section{Methods}

\section{Mice and cell lines}

All studies were performed on 202Mul and NK1Mul mice. To generate the mice with DNIIR-dominant-negative T $\beta$ RII (202Mul/DN and NK1Mul/DN) 202Mul or NK1Mul mice ordered from Jackson Laboratory (Bar Harbor, ME, USA) and mice with expressed dominant-negative T $\beta R I I$ were crossed [19]. The mice are proven to be on pure FVB background. The studies were approved by IACUC at Vanderbilt University Medical Center, Nashville, TN, USA.

The 202Mul and 202Mul/DN carcinoma cell lines were derived from primary tumors of 202Mul and 202Mul/DN mice, established and cultured in DMEM/F12 with 5\% adult bovine serum. These carcinoma cells were implanted into the mammary fat pad of the \#4 mammary gland via collagen plugs $(\mathrm{CP})\left(5 \times 10^{5}\right.$ cells/plug). $\mathrm{CP}$ were prepared by suspending carcinoma cells $\left(5 \times 10^{5} / \mathrm{plug}\right)$ in collagen solution $(50 \mathrm{mkl} / \mathrm{plug}$ ), followed by pipette of this mixture $(50 \mathrm{mkl})$ to 12 -well dishes and incubation at $37^{\circ} \mathrm{C}$ for 45 minutes to solidify the gel. Then $\mathrm{CP}$ were overlaid with medium and incubated for an additional 4 to 18 hours at 
$37^{\circ} \mathrm{C}$. The collagen mixture contained rat-tail collagen type I (BR Biosciences, San Jose, CA, USA), $10 \times$ Earle's Balanced Salt Solution (EBSS, Gibco), NaHCO3, $1 \mathrm{M} \mathrm{NaOH}$, and sterile $\mathrm{ddH}_{2} \mathrm{O}$. The size of tumors was determined by direct measurement of tumor dimensions at 2 to 3 day intervals using calipers.

\section{Flow cytometry analysis}

Single-cell suspensions were made from the spleens of tumor-bearing mice [20,21], and tumor tissues [22]. Excised tumors were chopped into small pieces, incubated in DMEM (Gibco, Life Technologies, Grand Island, NY, USA) with no serum, $1 \mathrm{mg} / \mathrm{mL}$ collagenase I (Sigma, St. Louis, MO, USA), and $1 \mathrm{mg} / \mathrm{mL}$ Dispase II (Roche) for 2 hours at $37^{\circ} \mathrm{C}$, and then passed through a cell strainer. Total cell numbers were counted, and $\mathrm{CD} 45^{+}$cell populations that represented tumor-infiltrating host immune cells were analyzed by flow cytometry. After treatment with FcR Blocking Reagent (Miltenyi Biotec Inc., Auburn, CA, USA), tumor single-cell suspensions $\left(10^{6}\right.$ cells $\left./ \mathrm{mL}\right)$ were labeled using fluorescein-conjugated antibodies (Abs) (Biolegend, eBiosciense, BD, all from San Diego, CA, USA) for 20 minutes on ice. Data acquisition was performed on a LSRII flow cytometer (BD Immunocytometry Systems, Franklin Lakes, NJ, USA), and the data were then analyzed with FlowJo software. Nonviable cells were excluded using 4',6-diamidino-2phenylindole (DAPI). Antigen negativity was defined as having the same fluorescent intensity as the isotype control.

\section{ELISA}

Cytokine levels in conditional media and tissue lysates were measured using the mouse CXCL1, CXCL5, MCP-1, VEGF, and IL-6 ELISA Duo kits (R\&D Systems, Minneapolis, MN, USA) following the manufacturer's protocol.

\section{Histology, IHC, and IF staining}

Tissues were embedded directly in an optimal cutting temperature compound without fixation or placement in $10 \%$ formalin overnight, and then embedded in paraffin and sectioned at $5 \mu \mathrm{m}$. Sections were de-waxed in xylene and rehydrated in successive ethanol baths. For immunohistochemistry (IHC), the MOM kit was used (Vector). H\&E and CD34 staining were performed in Translational Pathology Shared Resources (Vanderbilt University, Nashville, TN, USA). For immunofluorescence (IF) staining, primary and secondary antibodies were diluted in 12\% BSA, and then mounted in DAPI that contained a SlowFade medium (Invitrogen). Antibodies used for staining were NG2 (1:200; Abcam), CD31 (1:200; BD Biosciences), 5-bromo-2'-deoxyuridine (BrdU) (BD Biosciences). Quantification of staining was performed using ImageJ software (National Institutes of Health, Bethesda, MD, USA) in accordance with the recommended guidelines. H\&E and IHC sections were photographed using the OLYMPUS BX41 microscope and OLYMPUS DP2-BSW software. Slides for H\&E and CD34 staining of lungs were scanned using the Leica SCN400 slide scanner with $20 \times$ objective. Slides were photographed using a ZEISS Axioplan 2 microscope, and then numbered using MetaMorph software.

\section{Whole-lung mounting}

Mice were sacrificed by anesthetic overdose. Lungs were processed as described in the previously published article [23]. The tumor nodules in lungs were then counted.

\section{Cytokine antibody array}

Cells $\left(10^{6}\right)$ were plated on a 6 -wells plate in $3 \mathrm{~mL}$ of DMEM/F12 with $5 \%$ of adult bovine serum. Conditional medium was collected after 18 hours, and secreted proteins were screened using the RayBio Mouse Cytokine Antibody Array C Series 1000 (RayBiotech Inc., Norcross, GA, USA) according to the manufacturer's instructions.

\section{Western blot analysis}

Cells or tissue were lysed in radioimmunoprecipitation assay buffer containing protease inhibitors cocktail (Roche Diagnostics, Indianapolis, IN, USA). Total protein concentrations were quantified with the Pierce BCA Protein Assay Kit (Pierce Biotechnology, Rockford, IL, USA). Equal amounts of protein (30 to $60 \mu \mathrm{g} /$ well) were resolved in NuPAGE Novex 4 to $12 \%$ Bis-Tris polyacrylamide gel in the presence of $1 \times$ MES buffer (2-(N-morpholino)ethanesulfonic acid; Invitrogen) and transferred to a polyvinylidene fluoride membrane Immobilon-FL (Millipore Bioscience Research Reagents, Temecula, CA, USA). Anti-Akt (Cell Signaling, 9272), ph-Akt (Cell signaling, 4060), actin (Sigma, A2066) and secondary anti-Rabbit (Thermo Scientificm 31462) were used at 1:1,000, 1:1,000, 1:2,000 and 1:5,000 dilutions, respectively. After treatment with appropriate peroxidase-conjugated secondary antibody, the bands were visualized with an enhanced chemiluminescence method [24]. The intensity of protein bands was quantified by a densitometer using Image $1.45 \mathrm{~s}$ software (National Institutes of Health).

\section{Proliferation assays}

For in vivo experiments BrdU incorporation was used by injecting $100 \mu \mathrm{L}$ of $1 \mathrm{mg} / \mathrm{mL}$ BrdU 2 hours prior to performing euthanasia of animals. For in vitro experiments ${ }^{3} \mathrm{H}$-thymidine incorporation was performed for 2 hours prior to conducting measurement with a scintillation counter, whereby mean cpm were normalized to untreated cells. Cells were plated in 24-well culture dishes at $4 \times 10^{4}$ per well. TGF $\beta 1$ (R\&D Systems, 
Minneapolis, MN, USA) treatment was performed in normal serum-containing media for 24 hours.

\section{Statistical analysis}

Data were presented as mean \pm standard error of the mean (SEM). Multiple comparisons between the treatment groups and the control untreated group were performed using one-way analysis of variance (ANOVA) followed by Dunnett's procedure for multiplicity adjustment. Two-group comparisons were performed using the two-sample $t$-test. Among the 1,056 human breast tumor tissue samples from The Cancer Genome Atlas Breast Cancer (TCGA BRCA) depository, 531 samples have both gene expression and clinical data available and were therefore used for the following analysis. Samples with low versus high TßRII expression were compared to their CXCL1, CXCL5, MCP-1, IL-6, and VEGF expression levels usingthe Wilcoxon rank-sum test for all patients as well as stratified by estrogen receptor (ER), progesterone receptor (PR), and HER2 status separately. The findings were validated using six independent GEO datasets (4992, 6532, 2990, 12093, 3494, and 10886). However, HER2 status was not available in these GEO datasets. Breast cancer subtype classifiers were available in the literature. In this study patient subtype was predicted using the PAM50 classifier ( $R$ package, genefu 1.0.9 [25-27]). The association between distant metastasis-free survival (DMFS) and VEGF was analyzed using publicly available databases (GEO, EGA, and TCGA) for breast, ovarian, and human lung tumors from [28]. All tests are two-sided and significant at the $5 \%$ level. All statistical analysis for human breast cancer data was performed in R 3.0.2 [29].

\section{Results}

Attenuated TGF $\beta$ signaling increases tumor latency and metastasis in neu-induced mammary tumorigenesis

In our study, we used two MMTV-Neu-induced genetically engineered mouse (GEM) models of mammary cancer. Mice expressing inactivated ErbB2 (202Mul) [11] and mice expressing constitutively activated ErbB2 (NK1Mul) [13] were crossed with mice expressing a DNIIR [30]. Mice with intact TGF $\beta$ signaling in the mammary gland were the control group (202Mul, NK1Mul), and mice with modified TGF $\beta$ signaling comprised the experimental group (202Mul/DN, NK1Mul/DN). Our tumor models were slightly different compared to the models published several years ago by other investigators (Figure 1A) [16], where the authors used the MMTV-Neu mouse model with Y1144 (YB) and Y1227 (YD) mutation in ErbB2 to activate specific HER2 signaling pathway - Shc or Grb2, respectively [31].

Median tumor latency for 202Mul mice was 220 days (Figure 1B) and for activated $\mathrm{Neu}$ it was 161 days (Figure 1C). The addition of a DNIIR increased tumor latency to 301 days, $P=0.04$, for $202 \mathrm{Mul} / \mathrm{DN}$ mice and to 220 days, $P=0.02$, for NK1Mul/DN mice. Morphology of tumor tissue was analyzed at 5, 9, and 12 weeks after tumor palpation. No significant difference was observed in tumor weight at the last time point (12 weeks) between control and experimental groups (Figure 1D). Nonetheless, during initial stages of the experiment (5 weeks), tumors appeared to grow slower in DNIIR mice in comparison with the control mice.

In parallel with spontaneous tumorigenesis, we established mammary carcinoma cell lines and implanted them into mammary fat pads via CP. We observed similar kinetics to our spontaneous model where tumors expressing DNIIR grew slowly in the beginning of experiment, but achieved the same size as those without DNIIR expression by the time of sacrifice (Figure 1E).

To analyze lungs for metastasis, we sacrificed mice 12 weeks after conducting tumor palpation or implantation of carcinoma cells to the mammary fat pad. In all models, we observed a significant increase in the number of lung metastasis: 5.5 times higher in 202Mul mice $(P<0.001)$, almost 12 times higher in mice with activated Neu $(P=0.02)$ and 6.7 times higher in mice with orthotopic implantation of mammary carcinoma cells $(P=0.01)$ (Figure 1F, 1G). IHC staining for CD34 showed that most metastases were extravascular with increased vasculogenesis in mice with DNIIR (Additional file 1: Figure S1).

\section{Attenuated TGF $\beta$ signaling in the mammary gland increases tumor angiogenesis}

Tumor latency was the only significant difference observed in the two different Neu-induced tumor models NK1Mul versus 202Mul and NK1Mul/DN versus 202Mul/ DN (Figure 1B, C). Upon sacrifice, we found that vessels coming into and out of the tumor tissue are significantly larger in mice with DNIIR than in MMTV-Neu mice (Figure 2A). In orthotopically implanted CP with carcinoma cells, we found visually more abundant vasculature in mice with NK1Mul/DN tumors versus NK1Mul (Figure 2B). Examination of the histopathology of the primary tumor showed typical adenocarcinoma common to the MMTV$\mathrm{Neu}$ models for both type of mice (Figure 2C). NK1Mul/ DN tumors exhibited multiple zones of necrosis.

Also, we analyzed vessel structure by IHC staining for CD31, as a marker of endothelial cells, (Figure 2D) and found that vessels in DNIIR mice are larger in diameter with necrosis between them. Number of large vessels was dramatically increased in mice with DNIIR (Additional file 1: Figure S2). Similar to the primary tumor, lung metastases of DNIIR tumors have also increased vessel presence as observed in CD34 staining (Additional file 1: Figure S1). Visual increase in angiogenesis in mice with DNIIR (Figure 2B), encouraged us to analyze pericyte coverage of vessels in tumor tissue. We found fewer vessels 
A
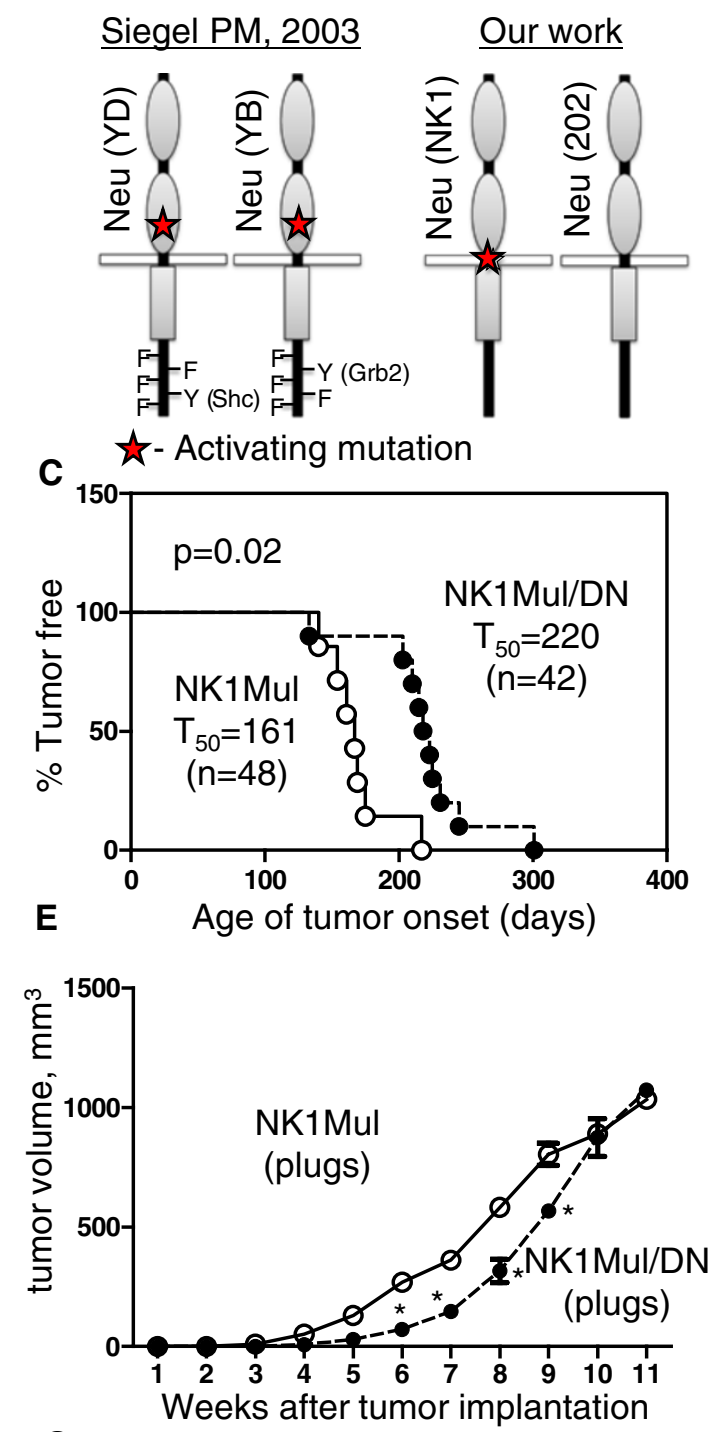

G

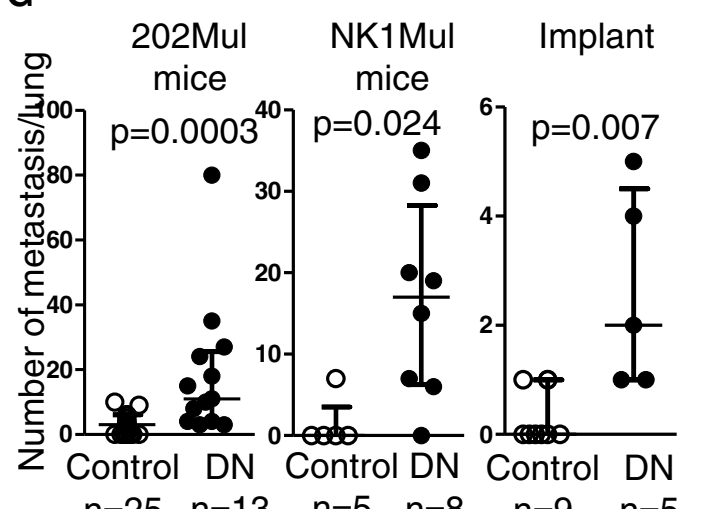

B
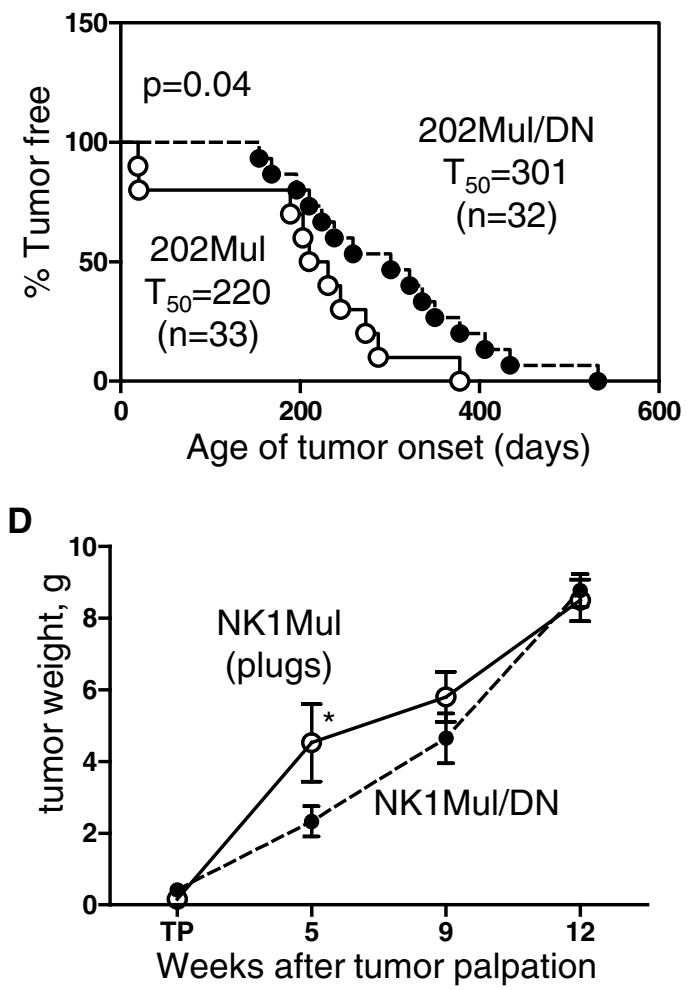

F
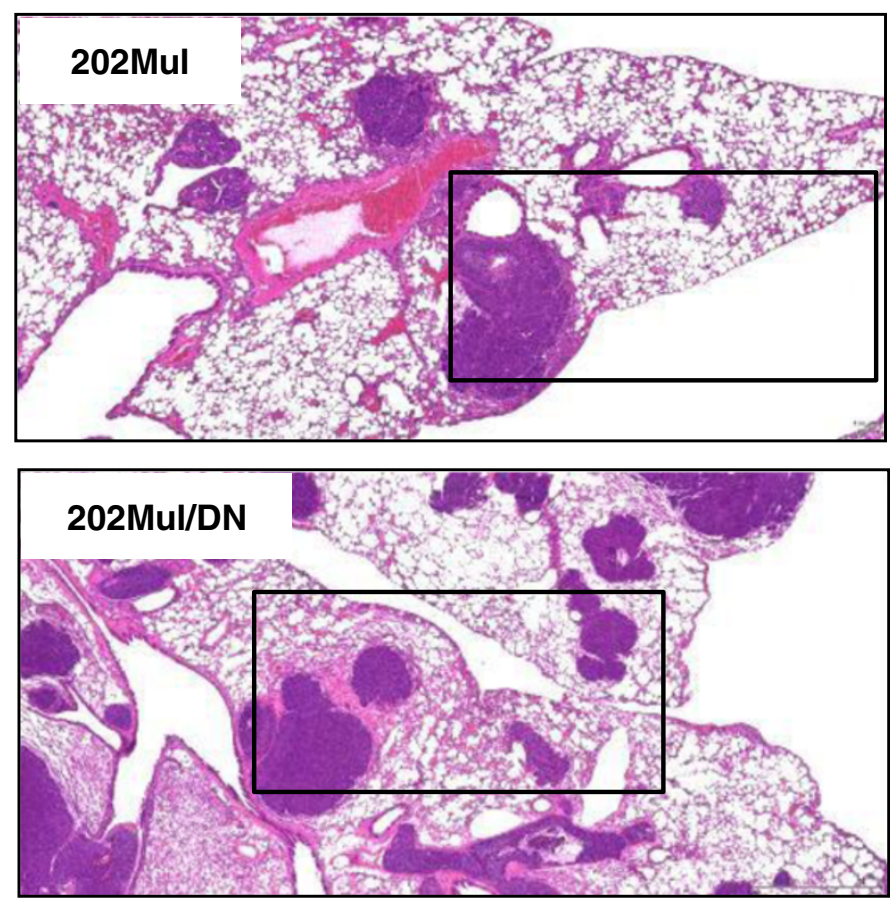

$(72 \%)(100 \%)(20 \%)(87 \%)(44 \%)(100 \%)$

Figure 1 (See legend on next page.) 


\begin{abstract}
(See figure on previous page.)
Figure 1 Tumor latency and metastasis in mouse mammary tumor virus (MMTV)-Neu mice with dominant-negative (DN) transforming growth factor $\beta$ (TGF $\beta$ ) receptor II (DNIIR). (A) Differences in two MMTV-Neu tumor models between a previously published model [16] and the models used in the current study. (B) Mammary tumor latency in 202Mul versus 202Mul/DN mice and (C) NK1Mul versus MK1Mul/DN mice. Age of onset is the time that a palpable mammary tumor first appears. $T_{50}$ denotes the age at which $50 \%$ of mice first possess a tumor, and $n$ is the number of mice examined. (D) Weight of tumor tissue in NK1Mul and NK1Mul/DN mice at different time points after tumor palpation. The total weight of tumors from all 10 mammary glands is indicated. (E) Tumor volume measured by caliper every 3 days after implantation into mammary fat pad via collagen plugs containing MMTV-Neu or MMTV-Neu/DNIIR carcinoma cell lines from NK1Mul or NK1Mul/DN mice, respectively. Five mice per group were used. (F) Representative H\&E sections illustrated metastasis in lungs of 202Mul and 202Mul/DN mice. Black box indicates area selected to represent CD34 IHC staining in Additional file 1: Figure S1. (G) Number of metastatic foci in lungs by using different tumor models: 202Mul mice, Nk1Mul mice and orthotopic implantation of carcinoma cells. Data shown on a scatter plot with median and interquartile range; $n$ is the number of mice examined; percentage indicates number of mice with metastasis; non-parametric Mann-Whitney test.
\end{abstract}

wrapped by pericytes in DNIIR mice (Figure 2E). To confirm this finding, we performed flow cytometry analysis of pericyte number in tumor tissue (Figure 2F, Additional file 1: Figure S2). Single-cell suspensions of tumor tissue were gated for non-immune $\left(\mathrm{CD} 45^{-}\right)$, non-epithelial (Ep-CAM $\left.{ }^{-}\right)$cells and detected as PDGFR $\beta^{+}$PDGFR $\alpha$. The number of these cells was decreased two-fold in NK1Mul/DN tumors versus NK1Mul tumors $(P=0.005)$. Based on increased angiogenesis, larger vessels, and deceased number of

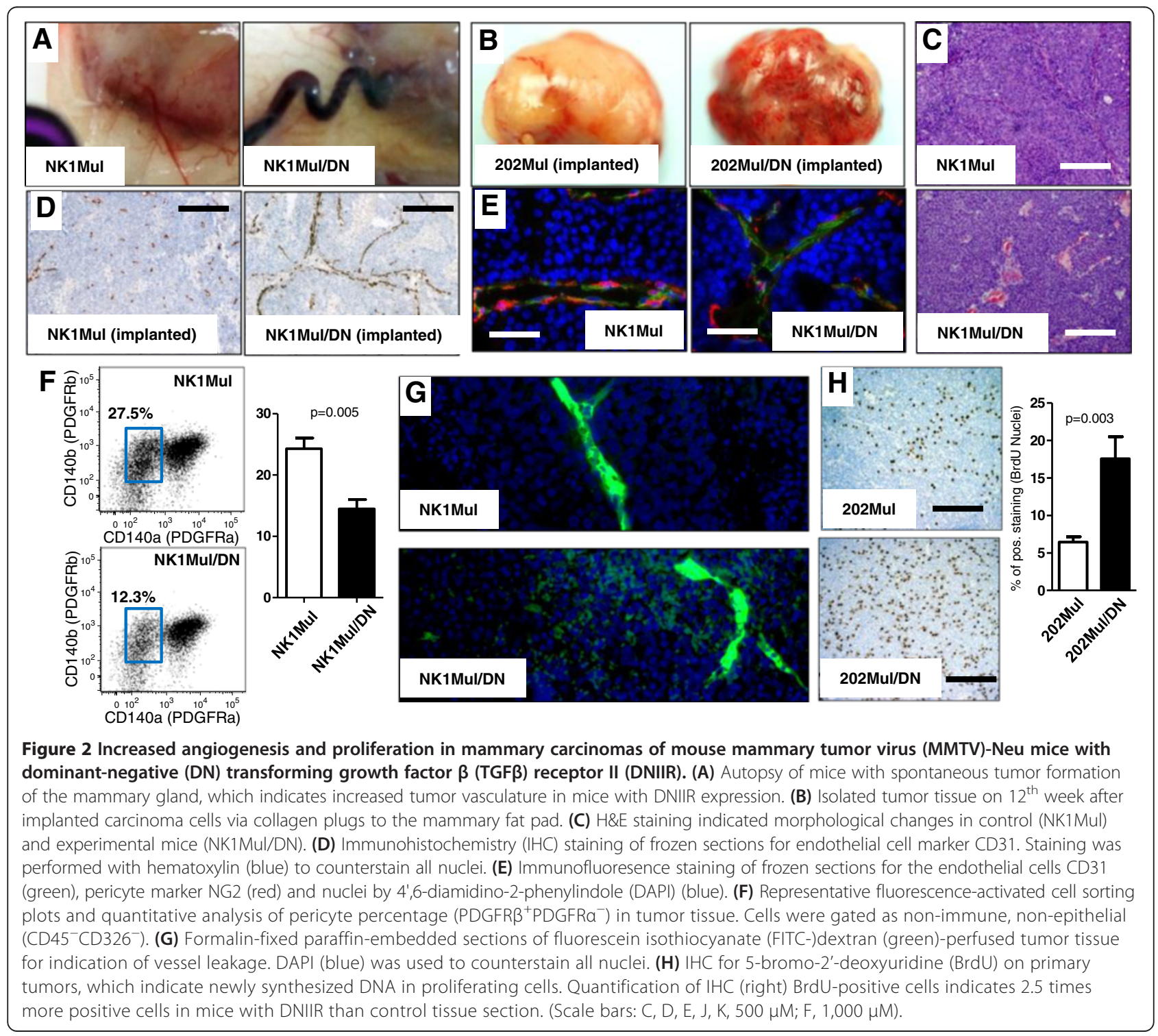


pericytes, we hypothesized that vessels in DNIIR mice would be leakier. To test this hypothesis, we performed intravenous injection of fluorescein isothiocyanate (FITC)-dextran and analyzed tumor tissue after tumor perfusion. IF imaging clearly indicated that Neu-induced tumors with DNIIR increased vessel leakage (Figure 2G). Thus, we propose that this is a potential factor for multiplication of lung metastases in DNIIR mice.

As we observed earlier, tumor weight and size were the same on the day of mouse sacrifice (Figure 1). However, we found that the proliferation rate on BrdU staining increased in mice with DNIIR (Figure 2H). DNIIR tumors grew slower after delayed tumor latency, but then presented increased tumor proliferation, potentially due to increased angiogenesis. As a result, DNIIR tumors caught up in size with MMTV-Neu tumors.

\section{Attenuation of TGF $\beta$ signaling reduces chemokine, but not VEGF expression, in the tumor microenvironment}

A classically defined role of TGF $\beta$ is the induction of cell-cycle arrest. To test the ability of DNIIR expression to attenuate this phenotype, we incubated established mammary carcinoma cell lines from 202Mul and 202Mul/DN mice with TGF $\beta$ for 24 hours at different concentrations. Starting from $0.5 \mathrm{ng} / \mathrm{mL}$ of TGF $\beta$, we observed inhibition of cellular proliferation in the presence of intact TGF $\beta$ signaling. In 202Mul/DN cells, TGF $\beta$ had an inhibitory effect compared with untreated cells, but a smaller magnitude of change in comparison with 202Mul cells (Figure 3A).

In PyMT-induced mammary tumorigenesis, deletion of TßRII was associated with a strong increase in secretion of CXCL1 and CXCL5 chemokines from mammary carcinoma cells [7-9] and significantly correlated with increased tumor progression and metastasis formation. We performed a protein array on tumor explant supernatants and found a significant decrease of monocyte chemotactic protein (1 MCP1) (CCL2), IL6, and tissue inhibitor of metalloproteinase (1 TIMP1) expression in cells expressing DNIIR (Figure 2B). To specify the cellular origin of chemokine changes, we used conditioned medium from cultured 202Mul and 202Mul/DN cells with/without TGF $\beta$ stimulation (Figure 3C). As in the tumor tissue, TGF $\beta$ upregulated IL- 6 and, VEGF, and downregulated MCP1, CXCL1, and CXCL5 in cells with and without DNIIR expression. Surprisingly, in cells with attenuated TGF $\beta$ signaling, we found dramatically decreased levels of CXCL1 and CXCL5, which were additionally downregulated by TGF $\beta$. DNIIR expression had a significant effect on VEGF secretion. Basal level of this cytokine was increased in 202Mul/DN cells compared to 202Mul cells and was strongly upregulated by TGF $\beta$, which correlated with the increased angiogenesis in mice with DNIIR (Figure 2A). To determine to what extent the levels of these chemokines change during tumor progression, we analyzed tumor tissue homogenates at 5 and 11 weeks after tumor palpation in NK1Mul and NK1Mul/DN mice (Figure 3D). The same effect was observed with CXCL1 and, more importantly, with VEGF. Comparison analysis of chemokines and VEGF secretion in MMTV-PyMT cells versus MMTV-Neu cells showed the same tendency, namely downregulation of CXCL5 and upregulation of VEGF in cells with DNIIR versus deletion of this receptor (Additional file 1: Figure S3).

\section{Attenuated TGF $\beta$ signaling in the MMTV-Neu tumor model decreases $\mathrm{T}$ cells and $\mathrm{CD} 11 \mathrm{~b}^{+} \mathrm{Gr} 1^{+}$cells in tumor tissue}

In our previous work on MMTV-PyMT tumors, we found that abrogation of TGF $\beta$ signaling in mammary epithelium increased chemokine production and the number of $\mathrm{CD} 1 \mathrm{~b}^{+} \mathrm{Gr} 1^{+}$cells in tumor tissue, which correlated with the increased metastasis [7,8]. Attenuated TGF $\beta$ signaling in Neu-induced tumorigenesis leads to different cellular responses, namely significant downregulation of CXCL1 and CXCL5. We analyzed tumor tissue and spleen from mice at 12 weeks after tumor palpation and found no differences in the number of $\mathrm{T}$ cells (CD3) and B cells (CD19) in the spleen (Additional file 1: Figure S4A). When we analyzed subsets of $\mathrm{T}$ cells (CD4 and CD8) we detected decreased number of $\mathrm{T}$ helpers (CD4) as well as an altered ratio of $\mathrm{CD} 4+$ to CD8+ cells (Additional file 1: Figure S4B). Expected

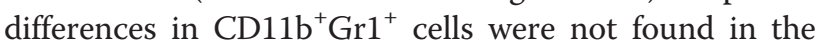
spleen (Additional file 1: Figure S4C).

In our analysis of tumor tissue, the total number of immune cells $\left(\mathrm{CD} 45^{+}\right)$did not alter (Additional file 1: Figure S2D). When we analyzed fluorescence-activated cell sorting (FACS) plots for CD11b and Gr1 staining we found no differences in the number of macrophages $\left(\mathrm{CD} 11 \mathrm{~b}^{+} \mathrm{Gr} 1^{-} \mathrm{F} 4 / 80^{+}\right)$, but detected a decreased number

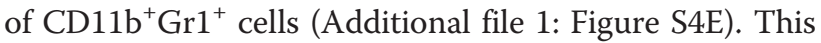
result was predicted due to downregulation of CXCL1 and CXCL5. Analysis of lymphocytes showed a decreased number of $\mathrm{T}$ cells (CD3) in NK1Mul/DN mice compared with the mice with intact TGF $\beta$ signaling. Because of the decreased number of $\mathrm{CD} 11 \mathrm{~b}^{+} \mathrm{Gr} 1^{+}$cells that can successfully inhibit $\mathrm{T}$ cell proliferation, we propose that the mechanism driving the decrease in $\mathrm{T}$ cells is not

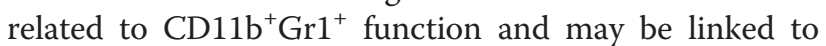
the increase of VEGF in tumor tissue [32].

\section{Attenuated TGF $\beta$ signaling in HER2+ tumors leads to increased pAKT}

There are numerous molecular mechanisms for the interaction between TGF $\beta$ and HER signaling during tumor growth, which were summarized in a recently published review [33]. We performed analysis for known components linking these two pathways. We then 


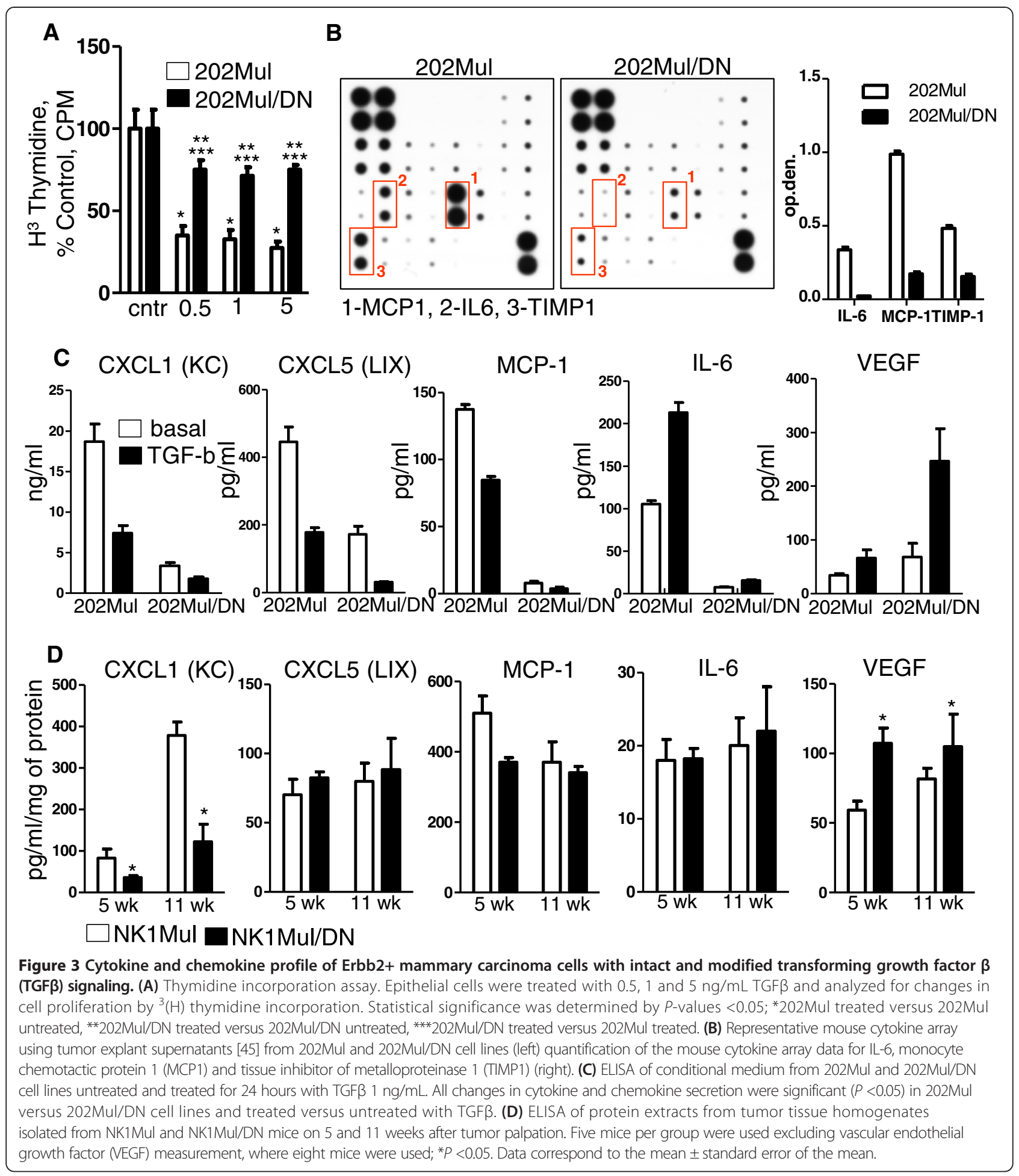

cultured carcinoma cells with TGF $\beta 1(1 \mathrm{ng} / \mathrm{mL})$ overnight and found increased phosphorylated AKT in cells with DNIIR compared to those without DNIIR (Figure 4A, Additional file 1: Figure S5). To determine differences in pAKT in tumor tissue, we prepared tissue homogenates at 5 and 12 weeks after tumor palpation. Total
AKT did not change, but we found increased pAKT in 202Mul/DN tumors compared to 202Mul tumors (Figure 4B). Quantitative data revealed significant differences at two time points, at 5 and 12 weeks of tumor progression in 202Mul/DN mice versus 202Mul mice. Additional western blot analysis did not 


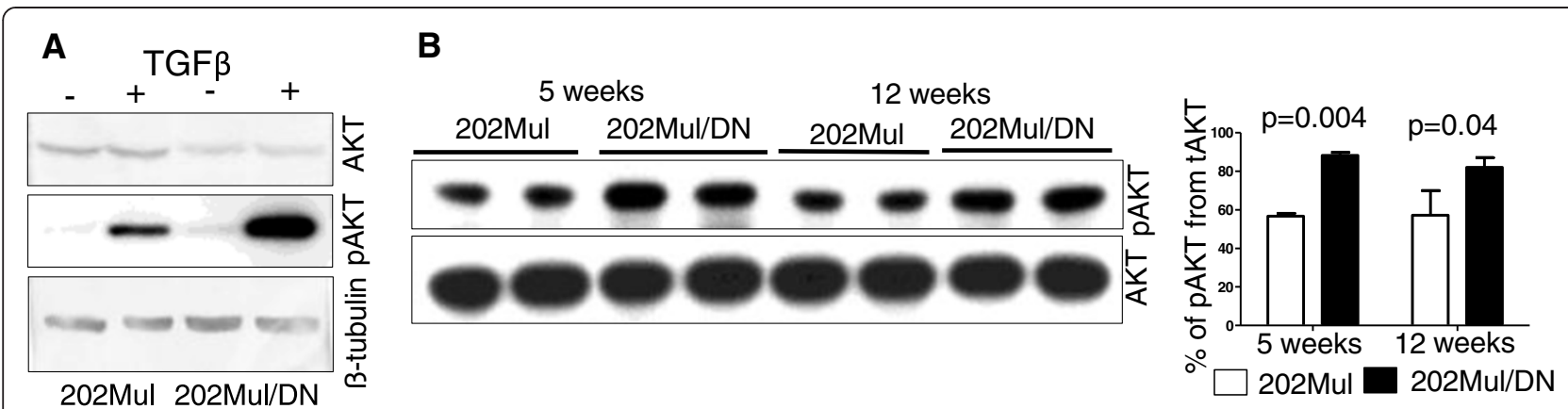

Figure 4 Western blot analysis of carcinoma cell lines and tumor tissues. (A) Western blot analysis of AKT and pAKT in 202Mul and 202Mul/ DN established mammary carcinoma cell lines incubated with transforming growth factor $\beta$ (TGF $\beta$ ) $1 \mathrm{ng} / \mathrm{mL}$ for 24 hours. (B) Western blot and quantitative analysis of AKT and PAKT in tumor tissue lysates at 5 and 12 weeks after tumor palpation. Open bars, 202Mul mice; closed bars, 202Mul/DN mice. Protein lysates for (A) and (B) were prepared through homogenization in Complete-M lysis buffer (Roche) and quantified by Bradford DC assay (Biorad). AKT and PAKT were detected using rabbit monoclonal antobody (Cell Signaling).

exhibit any differences in p53, PI3K, Rac1, Shc, ERK, MAPK or p38 expression with or without DNIIR expression (data not shown).

\section{Human data sets reflect similar findings with the mouse models}

To determine the relevance of our findings to human breast cancer, we analyzed microarray profiles of human breast cancer tissues with well-documented clinical data related to PR, ER and HER2 status and time of relapse detection over a 10-year period. In our mouse model, we found that attenuated TGF $\beta$ signaling in epithelial cells correlated with decreased CXCL1, CXCL5, MCP-1, IL-6 and increased VEGF expression. Therefore, we first conducted analysis of correlation between expression of the TGFBR2 gene and these genes. We found that expression of CXCL1, but not CXCL5, decreased significantly in patients with low TGFBR2 expression (Figure 5A, B), but when we analyzed subtypes of tumor we discovered significant differences only in HER2+, PR + and ER + patients. There was no change in PR-negative (PR-) and ER- patients. MCP-1 and IL-6 expression decreased in all patients with low levels of TGFBR2 expression, with no differences in subtypes of breast tumor (Figure 5C). By checking the association between VEGFA and TGFBR2 expression using the TCGA BRCA dataset, we detected an opposite effect to that seen with CXCL1, MCP-1 and IL-6. This inference is consistent with our findings in a mouse model. VEGF expression increased in patients with all types of tumors with low TGFBR2 expression (Figure $5 \mathrm{C}$ ). We further validated these analyses using PAM50 enrichment of HER2 patients from the aforementioned six human breast cancer GEO microarray datasets. The majority of the results are consistent with our previous findings from the TCGA data (Additional file 1: Figure S6). In all six datasets, attenuated TGF $\beta$ signaling was correlated with low CXCL1 expression among HER2-enriched patients. Attenuated
TGF $\beta$ signaling was also significantly correlated with low VEGF expression among all patients and HER2enriched patients in GSE10886; however, this conclusion was not validated in other datasets.

In our current study using the GEM tumor model, we indicated that metastasis is a major phenotype in mice with abrogated TGF $\beta$ signaling in the tumor epithelium. Next, we examined the association of the VEGF gene with tumor subtypes and DMFS and noted a significant association between high VEGFA expression and worse DMFS in HER2+ patients (Figure 5D). Nonetheless, there was not a statistically significant difference in patients with $\mathrm{ER}+, \mathrm{PR}+$, or other subtypes of breast cancer.

This research finding indicates that attenuated TGF $\beta$ signaling correlates with decreased expression of CXCL1 and increased VEGF expression and is associated with worse survival rates in HER2+ patients. The aforementioned results were confirmed on the Neu-induced mouse tumor and human breast cancer models.

\section{Discussion}

Important roles of TGF $\beta$ and HER2 signaling in tumor initiation and progression have been established in a large number of studies. To examine the role of TGF $\beta$ signaling in HER2+ breast cancer, we used MMTV-Neu mice with DNIIR. In our studies 202Mul mice with overexpression of wild-type ErbB2 and NK1Mul mice with mutant activated ErbB2 were utilized. In our experiment, we did not incorporate any specific pathways as was executed in the Siegel at al. publication [16]. In our analysis of the TCGA database (Additional file 1: Figure S7) we observed that in fewer than 5\% of patients ErbB2 mutated and in about $15 \%$ of patients the ErbB2 receptor was amplified. This result was supported by recently published work by Bose et al. [34], in which researchers observed ErbB2 mutation in only a small percentage of HER2+ patients. Based on this fact we believe that our GEM tumor model is highly appropriate for investigation 


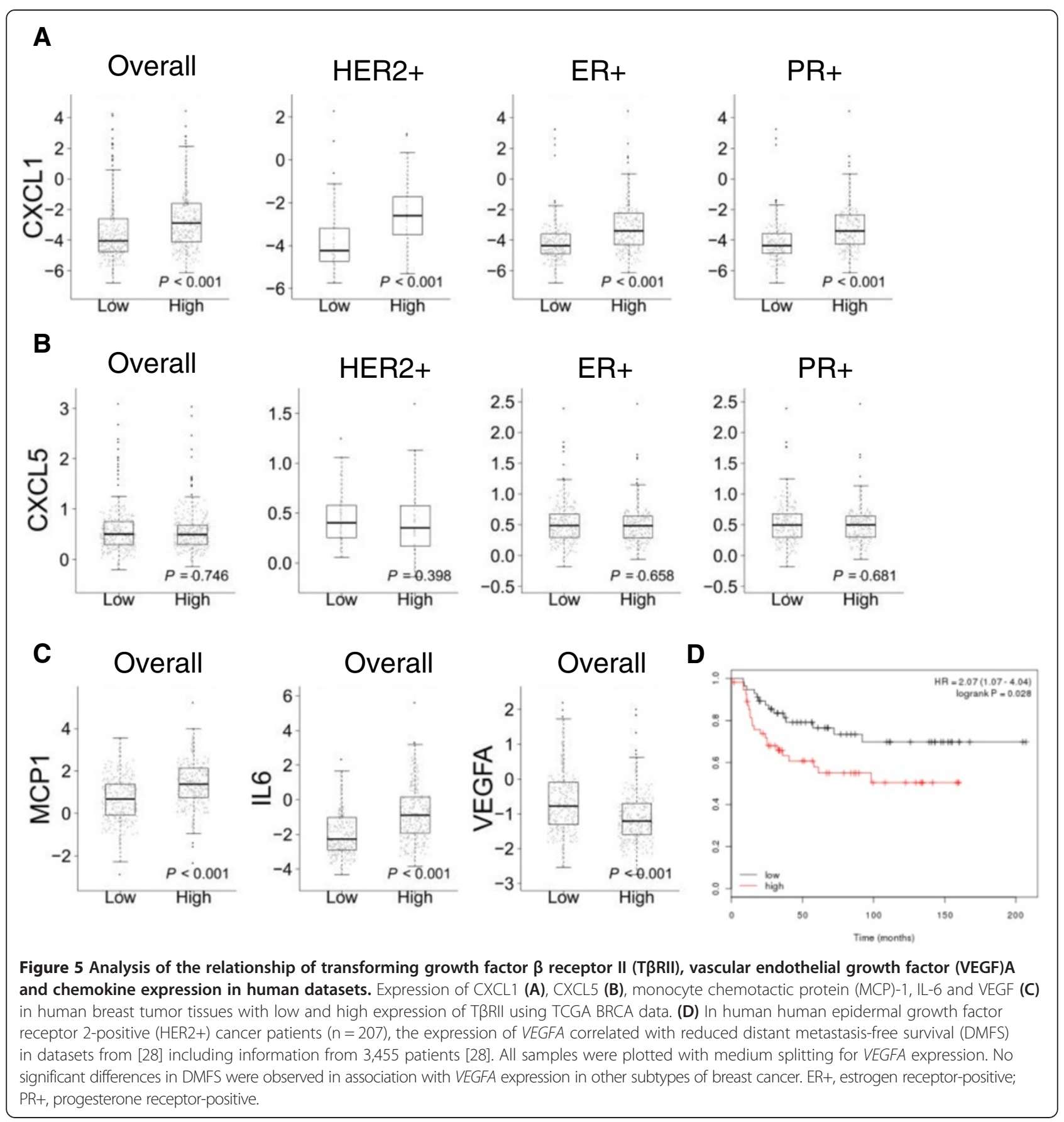

of the HER2+ type of breast cancer with attenuated TGF $\beta$ signaling.

In our GEM model the major differences between mice with intact and disrupted TGF $\beta$ signaling were increased tumor latency in parallel with the increased number of lung metastases (Figure 1). Changes in metastasis were different when compared with mouse models where ErbB2 was mutated by activated Grb2 or Shc signaling pathways [16]. The increased tumor latency was also opposite to MMTV-PyMT/TGF $\beta$ RII-KO mice with deletion of $T g f b r 2$ in the mammary epithelium [5], as previously studied in our laboratory. However, the increase in lung metastases in the MMTV-Neu/DNIIR mouse model was similar to MMTV-PyMT/TGFßRIIKO mice. This indicates that any manipulation to diminish TGF $\beta$ signaling in GEM models will lead to increased metastasis regardless of tumor-driving oncogenic transformations.

Increased tumor latency in MMTV-Neu/DNIIR mice (202Mul/DN, NK1Mul/DN) versus control mice (202Mul, 
NK1Mul) could be first due to cell-cycle dysregulation, where TGF $\beta$ signaling plays an important role, and second, due to dysregulation of chemokine expression. Feng et al. demonstrated that the immune cells provide a source of tropic support to transformed epithelial cells, just as they do to normal epithelium during wound healing, and play a primary role in tumor initiation [35]. We found that mice with DNIIR expression had downregulated levels of CXCL1 and CXCL5 (Figure 3) and as a result, fewer CD11b ${ }^{+} \mathrm{Gr} 1^{+}$ cells in tumor tissue (Additional file 1: Figure S3).

Based on our current study and Siegel et al. [19] we can make a basic conclusion that attenuated TGF $\beta$ signaling in HER2+ tumor models, with active Shc and Grb2 pathways, decreases the probability of lung metastasis development. With intact ErbB2, attenuated TGF $\beta$ signaling has the opposite effect in spite of the fact that tumor latency increases.

Tumor tissues in mice with DNIIR had increased vasculogenesis, increased vessel size, leakiness, and decreased number of pericytes (Figure 2). Clinical data showed that a low number of pericytes correlated with poor patient prognosis [36,37]. Simultaneously, disruption of pericytes also enhanced metastasis [38]. In parallel with a decreased number of pericytes, we discovered that the size of vessels in tumor tissue was larger in mice with DNIIR. We hypothesized that there were probably two different mechanisms involved in increased vasculogenesis in DNIIR mice; and increased angiogenesis in parallel with the disruption of vessel support by pericytes. It is likely that an increase in vessel leakage leads to an increased number of metastases [38].

In our previously published articles, we indicated that deletion of Tgfbr2 leads to an increase in chemokine expression in mammary and pancreatic epithelium [7,39]. Researchers have also linked deletion of $\mathrm{Tg} f b r 2$ to an increase in mammary fibroblasts [40]. In the mammary tumorigenesis studies, the major differences were found in CXCL1 and CXCL5 expression, which play an important role in the migration of neutrophils and myeloidderived suppressor cells $\left(\mathrm{CD} 11 \mathrm{~b}^{+} \mathrm{Gr} 1^{+}\right)$.

An increased number of myeloid cells in MMTVPyMT mice could be a basic mechanism driving decreased tumor latency and increased number of lung metastases. In our current study with attenuated TGF $\beta$ signaling in MMTV-c-Neu mice, we discovered an opposite effect in which levels of CXCL1/CXCL5 as well as CCL2 (MCP-1) decreased (Figure 3) in parallel with an increased level of VEGF. Comparison analysis of chemokine and VEGF secretions in MMTV-PyMT cells with DNIIR (Additional file 1: Figure S3) showed the same effect. There was an opposite result when TGFßRII was deleted. Our laboratory published a study [41], which showed that DNIIR system could not completely inhibit the non-canonical TGF $\beta$ pathway versus the canonical
(SMAD-dependent). This information correlates with our data on increased pAKT (Figure 4, Additional file 1: Figure S5) in MMTV-Neu/DNIIR cells, which is downstream of the non-canonical TGF $\beta$ pathway. We propose that it is a significant mechanism in the differential regulation of chemokines and VEGF secretion. We can conclude that the MMTV-Neu/DNIIR GEM tumor model is a model of spontaneous mammary carcinogenesis with a diminished canonical TGF $\beta$ pathway (SMAD-dependent) with the stillactive non-canonical TGF $\beta$ pathway. There is also a significant amount of data to support a dose-response mediating TGF $\beta$-induced phenotypic changes $[42,43]$. Thus, it is likely that the observed gene expression changes are the result of altered TGF $\beta$ response due to the specific amount of TGF $\beta$ induced in cells, which express the DNIIR. Such observations could not be made with conditional knockout of Tgfbr2 as TGF $\beta$ signaling is completely abrogated. Other authors also found increased levels of pAKT when combining activated TGF $\beta$ signaling (ALK5 $5^{\mathrm{T} 204 \mathrm{D}}$, TGF $\beta 1^{\mathrm{S} 223 / 225}$ ) with Neu-induced tumorigenesis [15,17]. It can be explained by overactivation of both the canonical and noncanonical TGF $\beta$ pathways. An increased level of VEGF can explain increased vasculogenesis and vessel leakage in MMV/c-Neu DNIIR mice and could likely be involved in the observed increase in lung metastases.

Previously, we found that deletion of Tgfbr2 leads to an

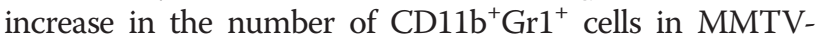
PyMT mice. In Neu-induced carcinogenesis, we did not observe many differences in immune components in mice with DNIIR versus control mice. The number of $\mathrm{CD}_{11} \mathrm{~b}^{+} \mathrm{Gr} 1^{+}$cells decreased in tumor tissue from MMTVc-Neu DNIIR mice that could result from downregulation of chemokines. Simultaneously the number of $\mathrm{T}$ cells decreased in parallel with the number of $\mathrm{CD} 11 \mathrm{~b}^{+} \mathrm{Gr} 1^{+}$cells in the MMTV-c-neu DNIIR tumors. Usually, increased num-

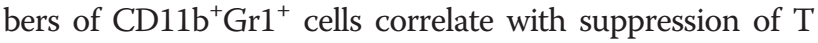
cell proliferation [44], but in our model we did not observe these changes to take place. Therefore, we suggest that decreased number of $\mathrm{T}$ cells could be due to the increased VEGF secretion in DNIIR mice. It has been shown that VEGF strongly inhibits T-cell development via VEGFR2 [32]. Also, VEGF receptors are capable of inhibiting dendritic cell function and, thus, we hypothesized that antitumor immune response in mice with DNIIR diminished as a result of higher levels of VEGF.

Based on these findings, we conclude that human HER2+ breast cancer associated with decreased TGF $\beta$ signaling would also correlate with deceased expression of CXCL1/5 chemokines and increased VEGF. We observed that decreased TGFBR2 expression in human breast cancer patients correlated with decreased CXCL1, but not with CXCL5 in HER2+, PR + and ER + tumors. MCP-1 and IL6 decreased and VEGF level increased in all types of breast tumors with low TGFBR2 expression. 
To our surprise, increased VEGF expression in human breast cancer patients correlated with reduced DMFS only in HER2+ patients. The same outcomes were observed in our mouse studies.

\section{Conclusion}

Our results demonstrated that attenuation of TGF $\beta$ signaling in HER2+ mammary epithelium delays tumor initiation, but promotes lung metastasis. The mechanism behind this phenomenon appears to be due to the increased VEGF secretion in parallel with deceased CXCL1 and CXCL5 secretion. The result of increased VEGF is increased tumor angiogenesis and vessel leakage that leads to an increase in lung metastasis. Also, increased VEGF secretion inhibits $\mathrm{T}$ cell proliferation and potentially inhibits anti-tumor immune response. Our studies provide insights into a novel mechanism by which epithelial TGF $\beta$ signaling modulates the tumor microenvironment and is involved in lung metastasis in HER2+ breast cancer patients. The effects of pharmacological targeting of the TGF $\beta$ pathway in vivo during tumor progression remain controversial because of the dual role TGF $\beta$ plays in tumor development. The targeting of TGF $\beta$ signaling should be considered as a viable option, but because VEGF has a pro-tumorigenic effect on HER2 + tumors, the targeting of this protein could be considered only when it is associated with attenuated TGF $\beta$ signaling.

\section{Additional file}

Additional file 1: Figure S1. CD34 immunohistochemistry analysis of mouse lungs. Figure S2. (A) Fluorescence-activated cell sorting (FACS) dot plots of pericyte analysis. FACS analysis of pericytes (CD140b + CD140a-) in single-cell suspension of tumor tissue. Cells were gated as alive (4',6-diamidino-2-phenylindole (DAPI)-) and gated as non-immune, non-epithelial (CD45-CD326-) as shown on the right side. (B) Distribution of tumor vessels within specified size ranges. Number of vessels detected on area equals 50,000 um2. Figure S3. ELISA data. Figure S4. Number of $\mathrm{T}$ cells and myeloid cells in spleen and tumor tissue. Figure $\mathbf{S 5}$. Western blot analysis of cultured cells. Figure S6. (A) The summary table of the additional datasets we have been observed; 1, data available; 0 , data not available. To replicate TCGA data we used the GSE10886 dataset, but it contains information only from 220 patients and only 11 are human epidermal growth factor receptor 2 (HER2)+. (B) The replication of plot 5A-C in the independent dataset GSE10886. Our findings in the manuscript are well-replicated in this dataset; however, as the new dataset sample size is small (in particular there are numerous missing values for estrogen receptor (ER), progesterone receptor (PR) and HER2), some of the $P$-values are not significant. Figure S7. Analysis (Cbioportal.org) of TCGA breast cancer molecular database for ErbB2 status. Bar graph depicts percentage of patients with either amplified or mutated ErbB2 of the total HER2+ patients. Comprehensive molecular portraits of human breast tumors. Nature, 2012. 490 (7418): p. $61-70$ (PDF 656 kb); (http://breast-cancer-research.com/content/ supplementary/s13058-014-0425-7-s1.pdf).

\section{Abbreviations}

BrdU: 5-bromo-2'-deoxyuridine; BSA: bovine serum albumin; CP: collagen plugs; DAPI: 4',6-diamidino-2-phenylindole; DMEM: Dulbecco's modified Eagle's medium; DMFS: distant metastasis-free survival; DNIIR: (or DN): dominant-negative TGF $\beta$ receptor II; ELISA: enzyme-linked immunosorbent assay; ER: estrogen receptor; FACS: fluorescence-activated cell sorting; FITC: fluorescein isothiocyanate; H\&E: hematoxylin and eosin; IF: immunofluorescence; IHC: immunohistochemistry; IL: interleukin; MCP: monocyte chemotactic protein; MMTV: mouse mammary tumor virus; Neu: (also known as ErbB2) human epidermal growth factor receptor 2 (HER2); PR: progesterone receptor; PyMT: Polyoma middle T antigen; TGF $\beta$ : transforming growth factor beta; T $\beta R I$ : transforming growth factor $\beta$ receptor I; TRRIl: transforming growth factor $\beta$ receptor II TIMP: tissue inhibitor of metalloproteinase; VEGF: vascular endothelial growth factor.

\section{Competing interests}

The authors declare that they have no competing interests.

\section{Authors' contributions}

SVN and EF were involved in study conception, all experiments and data analyses, and drafting of the manuscript. AEG and AC performed mice genotyping, isolation and establishment of mammary tumor cell lines. MA assisted in in vitro cell maintenance and experiment coordination. DP performed immunoblotting. PO, DRY and MWP provided critical insight about the study design and experimental interpretation. ZZ, FY and YS provided statistical data analysis of human cancer datasets. HLM was a primary contributor to study conception, design and experimental implementation. All authors read and approved the final manuscript.

\section{Acknowledgements}

This work was supported by NIH grants CA085492 and CA102162 to HLM, the TJ Martell Foundation, the Vanderbilt-Ingram Cancer Center, and the Robert J and Helen C Kleberg Foundation. NIH grant CA068485 provided core laboratory support.

\section{Author details}

'Cancer Biology Department, Vanderbilt-Ingram Cancer Center, Nashville, TN, USA. ${ }^{2}$ Department of Urologic Surgery, Vanderbilt-Ingram Cancer Center, Nashville, TN, USA. ${ }^{3}$ Department of Human Development, Peabody College, Vanderbilt University, Nashville, TN, USA. ${ }^{4}$ Division of Cancer Biostatistics, Department of Biostatistics, Vanderbilt University, Nashville, TN, USA. ${ }^{5}$ Vanderbilt University, 2220 Pierce Ave, PRB 612, Nashville, TN 37232, USA.

Received: 1 October 2013 Accepted: 5 August 2014

Published online: 04 October 2014

\section{References}

1. Bierie B, Moses HL: Tumour microenvironment: TGFbeta: the molecular Jekyll and Hyde of cancer. Nat Rev Cancer 2006, 6:506-520.

2. Gobbi H, Arteaga $\mathrm{CL}$, Jensen RA, Simpson JF, Dupont WD, Olson SJ, Schuyler PA, Plummer WD Jr, Page DL: Loss of expression of transforming growth factor beta type II receptor correlates with high tumour grade in human breast in-situ and invasive carcinomas. Histopathology 2000, 36:168-177.

3. Bottinger EP, Jakubczak JL, Roberts IS, Mumy M, Hemmati P, Bagnall $K$ Merlino G, Wakefield LM: Expression of a dominant-negative mutant TGF-beta type II receptor in transgenic mice reveals essential roles for TGF-beta in regulation of growth and differentiation in the exocrine pancreas. EMBO J 1997, 16:2621-2633.

4. Wang XJ, Greenhalgh DA, Bickenbach JR, Jiang A, Bundman DS, Krieg T, Derynck R, Roop DR: Expression of a dominant-negative type II transforming growth factor beta (TGF-beta) receptor in the epidermis of transgenic mice blocks TGF-beta-mediated growth inhibition. Proc Natl Acad Sci USA 1997, 94:2386-2391.

5. Forrester E, Chytil A, Bierie B, Aakre M, Gorska AE, Sharif-Afshar AR, Muller WJ, Moses HL: Effect of conditional knockout of the type II TGF-beta receptor gene in mammary epithelia on mammary gland development and polyomavirus middle T antigen induced tumor formation and metastasis. Cancer Res 2005, 65:2296-2302.

6. Bierie B, Stover DG, Abel TW, Chytil A, Gorska AE, Aakre M, Forrester E, Yang L, Wagner KU, Moses HL: Transforming growth factor-beta regulates mammary carcinoma cell survival and interaction with the adjacent microenvironment. Cancer Res 2008, 68:1809-1819.

7. Bierie B, Chung CH, Parker JS, Stover DG, Cheng N, Chytil A, Aakre M, Shyr Y, Moses $\mathrm{HL}$ : Abrogation of TGF-beta signaling enhances chemokine 
production and correlates with prognosis in human breast cancer. J Clin Invest 2009, 119:1571-1582

8. Yang L, Huang J, Ren X, Gorska AE, Chytil A, Aakre M, Carbone DP, Matrisian LM, Richmond A, Lin PC, Moses HL: Abrogation of TGF beta signaling in mammary carcinomas recruits $\mathrm{Gr}-1+\mathrm{CD} 11 \mathrm{~b}+$ myeloid cells that promote metastasis. Cancer Cell 2008, 13:23-35.

9. Novitskiy SV, Pickup MW, Gorska AE, Owens P, Chytil A, Aakre M, Wu H, Shyr Y, Moses HL: TGF-beta receptor II loss promotes mammary carcinoma progression by Th17 dependent mechanisms. Cancer Discov 2011, 1:430-441.

10. Matise LA, Palmer TD, Ashby WJ, Nashabi A, Chytil A, Aakre M, Pickup MW, Gorska AE, Zijlstra A, Moses HL: Lack of transforming growth factor-beta signaling promotes collective cancer cell invasion through tumor-stromal crosstalk. Breast Cancer Res 2012, 14:R98.

11. Guy CT, Webster MA, Schaller M, Parsons TJ, Cardiff RD, Muller WJ: Expression of the neu protooncogene in the mammary epithelium of transgenic mice induces metastatic disease. Proc Natl Acad Sci USA 1992 89:10578-10582.

12. Siegel PM, Ryan ED, Cardiff RD, Muller WJ: Elevated expression of activated forms of Neu/ErbB-2 and ErbB-3 are involved in the induction of mammary tumors in transgenic mice: implications for human breast cancer. EMBO J 1999, 18:2149-2164

13. Muller WJ, Sinn E, Pattengale PK, Wallace R, Leder P: Single-step induction of mammary adenocarcinoma in transgenic mice bearing the activated c-neu oncogene. Cell 1988, 54:105-115.

14. Hynes NE, Stern DF: The biology of erbB-2/neu/HER-2 and its role in cancer. Biochim Biophys Acta 1994, 1198:165-184.

15. Muraoka-Cook RS, Shin I, Yi JY, Easterly E, Barcellos-Hoff MH, Yingling JM, Zent R, Arteaga CL: Activated type I TGFbeta receptor kinase enhances the survival of mammary epithelial cells and accelerates tumor progression. Oncogene 2006, 25:3408-3423.

16. Siegel PM, Shu W, Cardiff RD, Muller WJ, Massague J: Transforming growth factor beta signaling impairs Neu-induced mammary tumorigenesis while promoting pulmonary metastasis. Proc Natl Acad Sci USA 2003, 100:8430-8435.

17. Muraoka RS, Koh Y, Roebuck LR, Sanders ME, Brantley-Sieders D, Gorska AE, Moses HL, Arteaga CL: Increased malignancy of Neu-induced mammary tumors overexpressing active transforming growth factor beta1. Mol Cell Biol 2003, 23:8691-8703.

18. Bandyopadhyay A, Lopez-Casillas F, Malik SN, Montiel JL, Mendoza V, Yang J, Sun LZ: Antitumor activity of a recombinant soluble betaglycan in human breast cancer xenograft. Cancer Res 2002, 62:4690-4695.

19. Gorska AE, Jensen RA, Shyr Y, Aakre ME, Bhowmick NA, Moses HL: Transgenic mice expressing a dominant-negative mutant type II transforming growth factor-beta receptor exhibit impaired mammary development and enhanced mammary tumor formation. Am J Pathol 2003, 163:1539-1549.

20. Yang L, DeBusk LM, Fukuda K, Fingleton B, Green-Jarvis B, Shyr Y, Matrisian LM, Carbone DP, Lin PC: Expansion of myeloid immune suppressor $\mathrm{Gr}+$ $\mathrm{CD} 11 \mathrm{~b}+$ cells in tumor-bearing host directly promotes tumor angiogenesis. Cancer Cell 2004, 6:409-421.

21. Novitskiy SV, Ryzhov S, Zaynagetdinov R, Goldstein AE, Huang Y, Tikhomirov OY, Blackburn MR, Biaggioni I, Carbone DP, Feoktistov I, Dikov MM: Adenosine receptors in regulation of dendritic cell differentiation and function. Blood 2008, 112:1822-1831.

22. Ljung BM, Mayall B, Lottich C, Boyer C, Sylvester SS, Leight GS, Siegler HF, Smith HS: Cell dissociation techniques in human breast cancer-variations in tumor cell viability and DNA ploidy. Breast Cancer Res Treat 1989, 13:153-159.

23. Jessen KA, Liu SY, Tepper CG, Karrim J, McGoldrick ET, Rosner A, Munn RJ, Young $\sqcup$, Borowsky AD, Cardiff RD, Gregg JP: Molecular analysis of metastasis in a polyomavirus middle T mouse model: the role of osteopontin. Breast Cancer Res 2004, 6:R157-R169.

24. Nesbitt SA, Horton MA: A nonradioactive biochemical characterization of membrane proteins using enhanced chemiluminescence. Anal Biochem 1992, 206:267-272

25. Parker JS, Mullins $M$, Cheang MC, Leung $S$, Voduc D, Vickery T, Davies $S$, Fauron C, He X, Hu Z, Quackenbush JF, Stijleman IJ, Palazzo J, Marron JS, Nobel AB, Mardis E, Nielsen TO, Ellis MJ, Perou CM, Bernard PS: Supervised risk predictor of breast cancer based on intrinsic subtypes. $J$ Clin Oncol 2009, 27:1160-1167.

26. Gatza ML, Lucas JE, Barry WT, Kim JW, Wang Q, Crawford MD, Datto MB, Kelley M, Mathey-Prevot B, Potti A, Nevins JR: A pathway-based classification of human breast cancer. Proc Natl Acad Sci USA 2010, 107:6994-6999.
27. Sorlie T, Tibshirani R, Parker J, Hastie T, Marron JS, Nobel A, Deng S, Johnsen H, Pesich R, Geisler S, Demeter J, Perou CM, Lønning PE, Brown PO, Børresen-Dale AL, Botstein D: Repeated observation of breast tumor subtypes in independent gene expression data sets. Proc Natl Acad Sci USA 2003, 100:8418-8423.

28. Gyorffy B, Lanczky A, Eklund AC, Denkert C, Budczies J, Li Q, Szallasi Z: An online survival analysis tool to rapidly assess the effect of 22,277 genes on breast cancer prognosis using microarray data of 1,809 patients. Breast Cancer Res Treat 2010, 123:725-731 [http://www.kmplot.com]

29. The language and environment for statistical computing and graphics. [http://www.r-project.org]

30. Gorska AE, Joseph H, Derynck R, Moses HL, Serra R: Dominant-negative interference of the transforming growth factor beta type II receptor in mammary gland epithelium results in alveolar hyperplasia and differentiation in virgin mice. Cell Growth Differ 1998, 9:229-238.

31. Dankort D, Maslikowski B, Warner N, Kanno N, Kim H, Wang Z, Moran MF, Oshima RG, Cardiff RD, Muller WJ: Grb2 and Shc adapter proteins play distinct roles in Neu (ErbB-2)-induced mammary tumorigenesis: implications for human breast cancer. Mol Cell Biol 2001, 21:1540-1551.

32. Huang Y, Chen X, Dikov MM, Novitskiy SV, Mosse CA, Yang L, Carbone DP: Distinct roles of VEGFR-1 and VEGFR-2 in the aberrant hematopoiesis associated with elevated levels of VEGF. Blood 2007, 110:624-631.

33. Chow A, Arteaga CL, Wang SE: When tumor suppressor TGFbeta meets the HER2 (ERBB2) oncogene. J Mammary Gland Biol Neoplasia 2011, 16:81-88.

34. Bose R, Kavuri SM, Searleman AC, Shen W, Shen D, Koboldt DC, Monsey J, Goel N, Aronson AB, Li S, Ma CX, Ding L, Mardis ER, Ellis MJ: Activating HER2 mutations in HER2 gene amplification negative breast cancer. Cancer Discov 2013, 3:224-237.

35. Feng $Y$, Santoriello C, Mione M, Hurlstone A, Martin P: Live imaging of innate immune cell sensing of transformed cells in zebrafish larvae: parallels between tumor initiation and wound inflammation. PLOS BiOl 2010, 8:e1000562.

36. O'Keeffe MB, Devlin AH, Burns AJ, Gardiner TA, Logan ID, Hirst DG, McKeown SR: Investigation of pericytes, hypoxia, and vascularity in bladder tumors: association with clinical outcomes. Oncol Res 2008, 17:93-101.

37. Stefansson IM, Salvesen HB, Akslen LA: Vascular proliferation is important for clinical progress of endometrial cancer. Cancer Res 2006, 66:3303-3309.

38. Xian X, Hakansson J, Stahlberg A, Lindblom P, Betsholtz C, Gerhardt H, Semb H: Pericytes limit tumor cell metastasis. J Clin Invest 2006, 116:642-651.

39. Ijichi H, Chytil A, Gorska AE, Aakre ME, Bierie B, Tada M, Mohri D, Miyabayashi K, Asaoka Y, Maeda S, Ikenoue T, Tateishi K, Wright CV, Koike K, Omata M, Moses HL: Inhibiting Cxcr2 disrupts tumor-stromal interactions and improves survival in a mouse model of pancreatic ductal adenocarcinoma. J Clin Invest 2011, 121:4106-4117.

40. Fang WB, Jokar I, Chytil A, Moses HL, Abel T, Cheng N: Loss of one Tgfbr2 allele in fibroblasts promotes metastasis in MMTV: polyoma middle T transgenic and transplant mouse models of mammary tumor progression. Clin Exp Metastasis 2011, 28:351-366.

41. Bhowmick NA, Zent R, Ghiassi M, McDonnell M, Moses HL: Integrin beta 1 signaling is necessary for transforming growth factor-beta activation of p38MAPK and epithelial plasticity. J Biol Chem 2001, 276:46707-46713.

42. Wu DT, Bitzer M, Ju W, Mundel P, Bottinger EP: TGF-beta concentration specifies differential signaling profiles of growth arrest/differentiation and apoptosis in podocytes. J Am Soc Nephrol 2005, 16:3211-3221.

43. Kale VP, Vaidya AA: Molecular mechanisms behind the dose-dependent differential activation of MAPK pathways induced by transforming growth factor-beta1 in hematopoietic cells. Stem Cells Dev 2004, 13:536-547.

44. Gabrilovich DI, Nagaraj S: Myeloid-derived suppressor cells as regulators of the immune system. Nat Rev Immunol 2009, 9:162-174.

45. Herber DL, Cao W, Nefedova Y, Novitskiy SV, Nagaraj S, Tyurin VA, Corzo A, Cho HI, Celis E, Lennox B, Knight SC, Padhya T, McCaffrey TV, McCaffrey JC, Antonia S, Fishman M, Ferris RL, Kagan VE, Gabrilovich DI: Lipid accumulation and dendritic cell dysfunction in cancer. Nat Med 2010, 16:880-886

doi:10.1186/s13058-014-0425-7

Cite this article as: Novitskiy et al:: Attenuated transforming growth factor beta signaling promotes metastasis in a model of HER2 mammary carcinogenesis. Breast Cancer Research 2014 16:425. 